\title{
Health and social care
}

\section{Editor}

Joe Bouch

\begin{tabular}{|c|c|c|}
\hline Editorial Board & Cornelius Katona & Trainee Editor \\
\hline Gwen Adshead & Helen Killaspy & Lisa Conlan \\
\hline J.S. Bamrah & Femi Oyebode & \\
\hline Dinesh Bhugra & Jan Scott & Editorial Assistant \\
\hline Nick Brown & Tom Sensky & Jonica Thomas \\
\hline Patricia Casey & Steven Sharfstein & \\
\hline David Castle & Michael Smith & Staff Editors \\
\hline John Cookson & Peter Tyrer & Kasia Krawczyk \\
\hline Jonathan Green & Marc Woodbury- & Lynnette Maddock \\
\hline Sheila Hollins & Smith & Zosia O'Connor \\
\hline $\begin{array}{l}\text { Sarah Huline- } \\
\text { Dickens }\end{array}$ & David Yeomans & \\
\hline
\end{tabular}

\section{Subscriptions}

Advances Volume 17, 2011 (six issues)

(full airmail £19/US\$34 extra)

\begin{tabular}{cc}
\hline $\begin{array}{c}\text { Members of the } \\
\text { Royal College } \\
\text { of Psychiatrists Non-members Institutions }\end{array}$ \\
\hline
\end{tabular}

Print (+free online)

$\begin{array}{lccc}\text { Europe (\& UK) } & £ 63 & £ 133 & £ 144 \\ \text { USA } & \text { US } \$ 112 & \text { US } \$ 209 & \text { US\$248 } \\ \text { Elsewhere } & £ 70 & £ 143 & £ 155\end{array}$

Online (only)

Worldwide

£40/US\$64 £105/US\$158 £131/US\$203

Payment may be made by cheque/money order, by Access/Master Card/ Visa/American Express, or by UNESCO coupons. EC subscribers: please supply your Member State Code and Value Added Tax (VAT) number.

Payment should be made to Maney Publishing, Suite 1C, Joseph's Well, Hanover Walk, Leeds LS3 1AB, UK (tel: +44 (0)113 243 2800; fax: +44 (0)113 386 8178; email: subscriptions@maney.co.uk). For subscriptions in North America, please contact Maney Publishing North America, 875 Massachusetts Avenue, 7th Floor, Cambridge, MA 02139, USA (tel: 866 2975154 (toll-free); fax: 617354 6875; email: maney@maneyusa.com). Continuing professional development (CPD) Those wishing to register for CPD with the Royal College of Psychiatrists should contact the CPD unit (tel: +44 (0)20 7235 2351, ext. 6108 or 6112). There is no charge for participation in the CPD scheme for Members, Fellows and Affiliates of the College.

CPD Online The College also publishes an interactive online learning facility for CPD in psychiatry. Further details, sample modules and subscription information can be viewed at www.psychiatrycpd.co.uk. Discounts are available for Advances subscribers.

Correspondence Letters submitted for publication should be emailed to Dr Joe Bouch at apt@rcpsych.ac.uk or posted to Advances in Psychiatric Treatment, Royal College of Psychiatrists, 17 Belgrave Square, London SW1X 8PG.

Printed by Henry Ling Ltd, 23 High East Street, Dorchester, Dorset DT1 1 HD.

(C) The Royal College of Psychiatrists 2011. Published by the Royal College of Psychiatrists, a charity registered in England and Wales (228636) and in Scotland (SC038369). Unless so stated, material in Advances in Psychiatric Treatment does not necessarily reflect the views of the Editor or the Royal College of Psychiatrists. The publishers are not responsible for any errors of omission or fact.

The College crest is a registered trade mark of the Royal College of Psychiatrists.

ISSN 1355-5146

\section{By Joe Bouch}

Many of our patients need both healthcare and social care, rather than one or other. Attempting to split care needs may feel counterintuitive to clinicians: for example, how should services for problem gambling be categorised (George \& Copello, pp. 318-322)? Even so, it has been argued that there is a health and social care divide - a 'Berlin Wall', contributed to by a series of barriers, including structural, financial and procedural (Glasby 2003). In addition, it is difficult to achieve effective partnership working between health and social care, particularly in the context of huge differences in power and culture between different occupational groups (Lymbery 2006). In some areas, such as implementation of Section 136 of the Mental Health Act 1983, psychiatrists have a clear leadership role, with involvement in setting standards (Hampson, pp. 365-371). In other areas, such as problem gambling, our involvement might at best be as part of 'a coalition of the willing' (George $\&$ Copello, pp. 318-322).

Two-thirds of people in Britain's care homes have dementia, a disease that is 'one of the greatest health and social care challenges facing the world today' (Burns 2011). Agitation is a common and distressing symptom in the care home population. It is associated with behavioural disturbance, including aggression. Treatment with antipsychotics may be neither safe nor effective, but no other drugs have been shown to be of value in reducing agitation - although effective pain management may help. However, there is increasing evidence of the efficacy of systematic non-drug-based interventions (Rosenberg 2011). Hence, the importance of psychiatrists contributing to developing the skills of the care workers who provide dayto-day care could hardly be overstated (Mason \& Adeshina, pp. 372-380).

\section{Improving care workers' skills}

Evidence-based medicine 'essentially involves integrating individual clinical expertise with the best available evidence from current research' (Wallace, pp. 389-395). Thus, clinicians might contribute to the 'bottomup development of a "what works and how" literature base which can inform others' (Sarkar \& di Lustro, pp. 323-331). My Editor's pick this month, by Mason $\&$ Adeshina (pp. 372-380), is an exemplar of this approach. The authors distil weak (level 4) evidence into a clear set of pragmatic principles emphasising the importance of three stages of effective training: predisposing, enabling and reinforcing. Thus, knowledge and attitudes are informed through small-group interactive sessions; changes in the working environment allow workers to implement their new skills; motivational approaches, support, advice and feedback facilitate implementation. The authors suggest that these principles apply to dementia care in all settings. I think that the principles are more generally applicable for all psychiatrists who work across the health and social care divide.

Burns A (2011) Care not control. Summons Summer issue: in press (http://www.mddus.com/mddus/publications/ summons.aspx).

Glasby J (2003) Bringing down the 'Berlin Wall': the health and social care divide. British Journal of Social Work 33: 969-75.

Lymbery M (2006) United we stand? Partnership working in health and social care and the role of social work in services for older people. British Journal of Social Work 36: 1119-34.

Rosenberg PB, Lyketsos CG (2011) Treating agitation in dementia. BMJ 343: d3913. 